\title{
Functional dissection of the ash2 and ash I transcriptomes provides insights into the transcriptional basis of wing phenotypes and reveals conserved protein interactions
}

\author{
Sergi Beltran $^{\star}$, Mireia Angulo ${ }^{\ltimes}$, Miguel Pignatelli, Florenci Serras and \\ Montserrat Corominas
}

\author{
Address: Departament de Genètica, Universitat de Barcelona, Diagonal 645, 08028 Barcelona, Spain. \\ $x$ These authors contributed equally to this work. \\ Correspondence: Montserrat Corominas. Email: mcorominas@ub.edu
}

Published: 28 April 2007

Genome Biology 2007, 8:R67 (doi:10.1 I86/gb-2007-8-4-r67)

The electronic version of this article is the complete one and can be found online at http://genomebiology.com/2007/8/4/R67
Received: 4 December 2006

Revised: 5 March 2007

Accepted: 28 April 2007

(C) 2007 Beltran et al.; licensee BioMed Central Ltd.

This is an open access article distributed under the terms of the Creative Commons Attribution License (http://creativecommons.org/licenses/by/2.0), which permits unrestricted use, distribution, and reproduction in any medium, provided the original work is properly cited.

\begin{abstract}
Background: The trithorax group (trxG) genes absent, small or homeotic discs I (ash I) and 2 (ash2) were isolated in a screen for mutants with abnormal imaginal discs. Mutations in either gene cause homeotic transformations but Hox genes are not their only targets. Although analysis of double mutants revealed that ash2 and ashl mutations enhance each other's phenotypes, suggesting they are functionally related, it was shown that these proteins are subunits of distinct complexes.

Results: The analysis of wing imaginal disc transcriptomes from ash2 and ash / mutants showed that they are highly similar. Functional annotation of regulated genes using Gene Ontology allowed identification of severely affected groups of genes that could be correlated to the wing phenotypes observed. Comparison of the differentially expressed genes with those from other genome-wide analyses revealed similarities between $\mathrm{ASH} 2$ and $\mathrm{Sin} 3 \mathrm{~A}$, suggesting a putative functional relationship. Coimmunoprecipitation studies and immunolocalization on polytene chromosomes demonstrated that $\mathrm{ASH} 2$ and $\mathrm{Sin} 3 \mathrm{~A}$ interact with $\mathrm{HCF}$ (host-cell factor). The results of nucleosome western blots and clonal analysis indicated that $\mathrm{ASH} 2$ is necessary for trimethylation of the Lys 4 on histone 3 (H3K4).

Conclusion: The similarity between the transcriptomes of ash2 and ash I mutants supports a model in which the two genes act together to maintain stable states of transcription. Like in humans, both $\mathrm{ASH} 2$ and $\mathrm{Sin} 3 \mathrm{~A}$ bind HCF. Finally, the reduction of $\mathrm{H} 3 \mathrm{~K} 4$ trimethylation in ash2 mutants is the first evidence in Drosophila regarding the molecular function of this trxG gene.
\end{abstract}

\section{Background}

During early development, transcription factors and signalling molecules initiate a cascade of developmental decisions that culminates in lineage restriction, cell determination and cell differentiation. However, commitment to a particular cell fate in the early embryo must be maintained throughout 
development, even after the factors that specified the cell fate are no longer present. The trithorax group (trxG) and Polycomb group ( $\mathrm{PcG}$ ) proteins are positive and negative regulators, respectively, that are involved in maintaining heritable patterns of transcription during development and differentiation (recently reviewed in [1-3]). Although the way in which trxG and PcG proteins recognize their target genes is not fully understood, Polycomb and trithorax response elements (generally termed PREs) are known to play an important role in this process, since they represent the DNA sequences upon which trxG and PcG complexes are assembled (for a review, see [3]). Genetic studies in Drosophila have shown that mutations in trxG and PcG genes result in flies with homeotic transformations due to inappropriate expression of Hox genes [4-6]. However, Hox genes are not the only targets [79]. The absent, small or homeotic discs 2 (ash2) gene is a member of the trxG that was discovered, together with ash1, in a screen for late larval and early pupal lethal mutations that generated abnormal imaginal discs [10]. Mutations in ash2 and ash 1 cause the homeotic transformations expected for this group and, in the case of ash2, a variety of pattern-formation defects in the wings [7,10-13]. Moreover, since analysis of double mutants reveals that ash2 and ash1 mutations enhance each other's phenotypes, it is likely that the genes are functionally related [13].

Using the fly wing as a model system, several approaches have been used to gain insight into the role of ASH2. Loss-of-function mutations in ash2 result in extra vein tissue and we have demonstrated through genetic analysis, clonal analysis and expression analysis of candidate genes that ash2 is involved in the maintenance of intervein cell identity $[11,12]$. Further insights have been gained using microarrays covering onethird of the Drosophila genome to analyze gene expression in whole larvae, an approach that identified several genes involved in the cell cycle, cell proliferation and cell adhesion, which are regulated by ash2 in larval tissues [7].

PcG and trxG proteins are assembled into dynamic multimeric complexes, several of which have been purified from organisms ranging from yeast to humans $[14,15]$. Although no biochemical studies in Drosophila have fully described the complexes in which ASH1 and ASH2 are involved, it has been shown that they are subunits of distinct complexes [16] and, in addition, it has been reported that ASH2 binds SKTL, a putative nuclear phosphatidylinositol 4-phosphate 5-kinase [17].

In Saccharomyces cerevisiae, two proteins (Bre2 and Spp1) have been proposed to associate to give a full ASH2 analogue in the complex termed Set1C $[18,19]$ or COMPASS [20], which can methylate the Lys4 on histone $3\left(\mathrm{H}_{3} \mathrm{~K}_{4}\right)[18,19]$. In mammals, ASH2 has been found in the COMPASS counterpart [21], in ASCOM [22], in two Menin-containing complexes $[23,24]$ and in a histone methyltransferase complex bound by host cell factor 1 (HCF-1) [25]. It has recently been shown that mammalian ASH2 plays a role in the trimethylation of $\mathrm{H}_{3} \mathrm{~K} 4$, a modification associated with transcriptionally active genes [26]. The presence of ASH2 in such a wide variety of complexes is an indication that it must be involved in the regulation of many different processes. ASH1 contains a SET domain and is an $\mathrm{H}_{3} \mathrm{~K}_{4}, \mathrm{H}_{3} \mathrm{~K} 9$ and $\mathrm{H}_{4} \mathrm{~K} 20$ methyltransferase $[27,28]$ required to prevent transcriptional repression by members of the PcG in Drosophila [29].

Systematic examination of gene expression patterns using whole-genome techniques, principally microarrays, allows the identification of most or all genes engaged in specific developmental processes [30,31]. However, simply listing genes associated with a certain tumor or developmental stage is insufficient to identify the biological processes in which these genes are involved, and comparative approaches are probably necessary to obtain a broader, yet more informative, picture of the phenomena under investigation. The work presented here is the first attempt to compare three alleles (ash2 $2^{112411}, a s h 2^{{ }^{11}}$ and $a s h 1^{22}$ ) from two trxG proteins (ASH2 and ASH1) by analysis of their transcriptome using tools based on Gene Ontology (GO) [32,33] and comparisons with published genome-wide data arising from microarray analysis or in silico predictions. Using this approach, we have been able to finely dissect the biological processes altered by mutations in ash2 and ash1 and to assess the similarity between them. We show that, despite the different nature of the ash $2^{112411}$ and $a s h 2^{I 1}$ alleles, their transcriptomes are very similar. Furthermore, we present data indicating that ASH1 and ASH2 act upon similar biological processes and genes, supporting the observation that ash2 and ash1 are functionally related. Moreover, since the number of regulated genes common to both ash2 and $\operatorname{Sin} 3 A$ mutants is higher than expected, we performed immunoprecipitation experiments that show that, as already reported in humans, Sin3A and ASH2 can both bind HCF [25]. Finally, we have detected a severe reduction of $\mathrm{H}_{3} \mathrm{~K}_{4}$ trimethylation in ash2 mutants, which suggests that ASH2 might play a role in methyltransferase activity while associating with complexes similar to those found in yeast and humans.

\section{Results and discussion Whole genome analysis of ash $I$ and ash2 mutant wing imaginal disc}

To characterize the molecular signature of ash1 and ash2 mutant wing discs, we compared whole genome expression profiles in wing imaginal discs from bromophenol bluestaged third instar larvae for the alleles ash2 $2^{I 1}, a s h 2^{112411}$ and $a s h 1^{22}$ with those from an isogenic line used as a common reference. The $a s h 2^{I 1}$ allele is lethal in late larval or early pupal stages whereas ash2112411 is a weaker allele that, although lethal at the pharate stage, presents a low percentage of adults $[11,12]$. The null $a s h 1^{22}$ allele is a late larval/early pupal lethal [34]. The wing disc phenotype associated with $a s h 2^{I_{1}}$ discs 


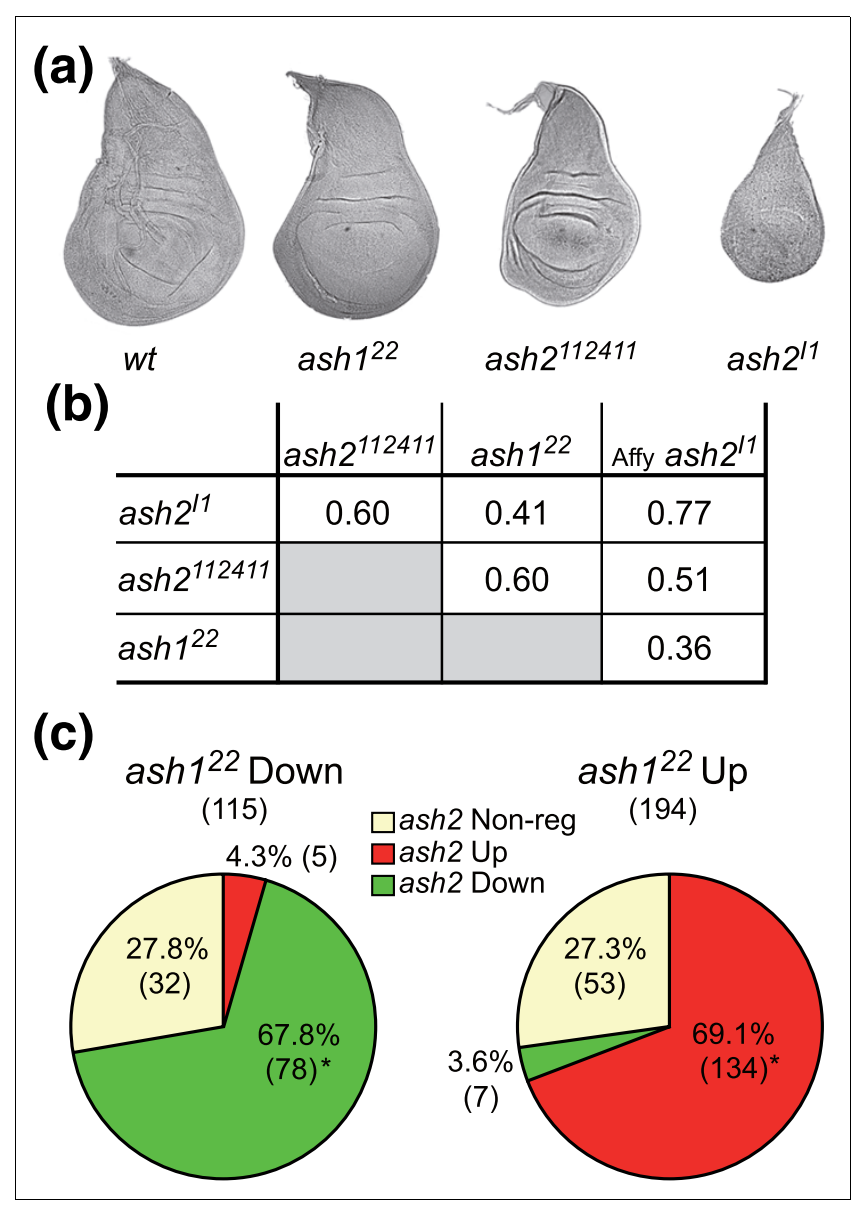

Figure I

Similarity of ash 2 and ash I mutant transcriptomes. (a) Wing imaginal discs of wt and ash 22 $^{2}$, ash2 112411 and ash2"l homozygotes. (b) Pearson's correlation coefficients between the normalized mean $\log _{2}$ ratios of the different experimental conditions. (c) Comparison of gene expression changes in ash $/ 22$ and ash 2 mutants. The circles represent the genes that were downregulated (left) or upregulated (right) with a greater than I.5fold change in ash / 22 mutants. The percentage of these genes that were also downregulated (green) or upregulated (red) in one or both of the ash2 alleles is shown. The absolute number of genes is shown in brackets. *Statistically significant overlap: $p=4.76 \times 10^{-56}$ (left) and $p=2.40 \times 10^{-104}$ (right).

involves abnormal shape and severe reduction in size, while ash2 $2^{112411}$ and $a s h 1^{22}$ discs are less affected (Figure 1a).

We performed a series of two-color microarray experiments with these alleles and obtained, for each of them, lists of genes showing greater than 1.5- or 2.0-fold changes in expression (Additional data files 2-4). The number of genes that were misregulated in each experimental condition is summarized in Additional data file 1 and all data are deposited in the Gene Expression Omnibus (GEO) database [35,36] with accession number GSE4923. In accordance with the phenotypes of these alleles, there were many less misregulated genes in ash 1 than in ash2 mutants.
To estimate the reproducibility of the results across platforms, two Affymetrix GeneChips were hybridized in a different laboratory with independently extracted $a s h 2^{I 1}$ RNA and reference RNA, respectively. We calculated Pearson's correlation coefficients for all the microarray results, including Affymetrix (Figure 1b). The highest similarity observed was between the two-color and the Affymetrix microarrays hybridized with $a s h 2^{I 1}$ and reference RNA, highlighting the quality of the data obtained.

\section{Functional dissection of the ash I and ash2 transcriptomes}

Comparison of genes showing significant levels of misexpression between ash 2 and ash 1 alleles revealed an extremely high and significant overlap between genes regulated in the same direction (Figure 1c) and the correlation coefficients were consistent with the wing disc phenotypes and lethality phases observed for the different alleles. Since we also intended to assess the similarity between the three alleles in more general terms, automatic functional annotation of all results was performed based on GO (Additional data files 516 and 22 and 23). Although this type of annotation is very useful to obtain a description of the transcriptome, it can be misleading if the absolute number of genes that fall into each class is used as the only factor for selection of relevant classes. Consequently, we identified which GO terms were significantly over-represented in each mutant allele under study. If ash2 and ash1 did not have specific functions, we would expect misregulated genes to fall into various GO categories and that the proportion of the genes in each category would be the same as the proportion of all Drosophila genes found in that category. However, as shown in the examples of GO terms given to misregulated genes in Figure 2a, more genes than expected by chance were involved in certain processes or functions. The bars (grey for downregulated and black for upregulated genes) indicate whether there are more (positive values) or less (negative values) genes with a given GO term than expected with a random distribution. For instance, out of the 526 underexpressed genes identified in ash $2^{I 1}$ mutants, 440 were annotated in the GO database. If these genes were randomly distributed, we would expect 6 of them to have the GO term 'wing disc development', since only $1.3 \%$ of all Drosophila genes with GO annotations have that term. However, 18 of the 440 genes held that descriptor (4.1\%), representing a 3 -fold enrichment in relation to the number expected by chance. This change corresponds to the size of the grey bar (downregulated genes) in the row 'wing disc development' for the $a s h 2^{I 1}$ allele (see also Additional data file 5).

While the two ash2 alleles affected the same processes almost identically, the ash 1 mutant displayed some slight differences (Figure 2a,b). Even though the significantly misexpressed genes were not identical between the three alleles, the expression of most genes tended to change in the same direction. The great similarity observed between the transcriptomes correlates with the similarities between the mutant 
(a)

\begin{tabular}{|c|c|c|c|c|c|c|}
\hline GENEONTOLOGY TERM & & $h 2^{11}$ & ash & 112411 & & $h 1^{22}$ \\
\hline Development & & & & * & & * \\
\hline Organ development & & & & $\square$ * & & \\
\hline Wing disc development & & $\square$ * & & * & $\mathbf{N}$ & $\square$ \\
\hline Dorsal/ventral p. f., imaginal disc & & 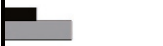 & & $\square$ & & 0 \\
\hline Anterior/posterior p. f., imaginal disc & & + & & $\square$ & & \\
\hline Death & & & & * * & & P \\
\hline Regulation of growth & & + & & + & & $\square$ \\
\hline Mitochondrion & $\square$ & & ᄃ & $a *$ & $\square$ & \\
\hline Mitochondrial ribosome & $\mathrm{N}$ & & $\mathrm{N}$ & & $\mathbf{N}$ & \\
\hline $\begin{array}{l}\text { Set of downregulated genes } \\
\text { Set of upregulated genes }\end{array}$ & 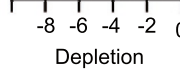 & $\begin{array}{lllll}0 & 2 & 4 & 6 & 8 \\
0 & \text { Enrichment }\end{array}$ & 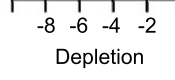 & $\begin{array}{llll}2 & 4 & 6 & 8 \\
\text { Enrichment }\end{array}$ & 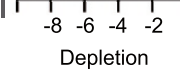 & $\begin{array}{llllll}0 & 2 & 4 & 6 & 8 \\
0 & & \\
& \text { Enrichment }\end{array}$ \\
\hline
\end{tabular}

(b)

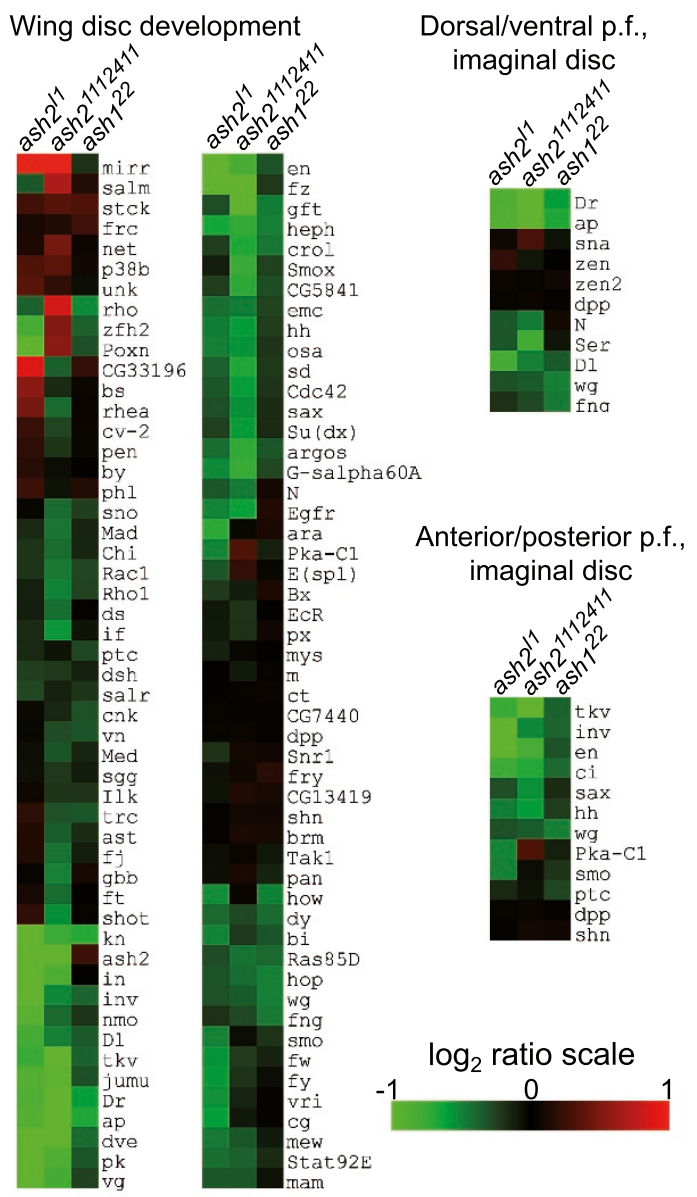

(c)

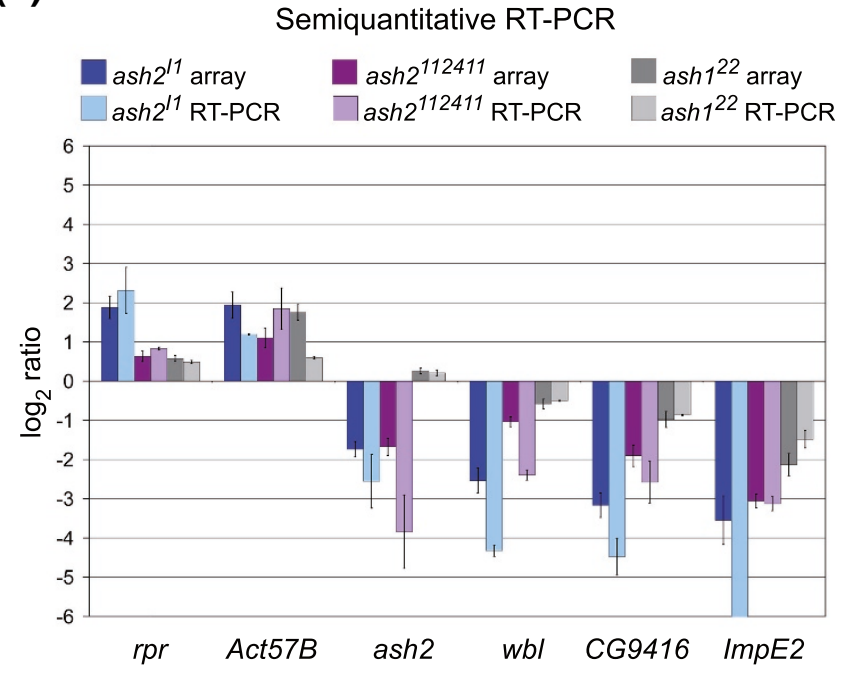

(d)
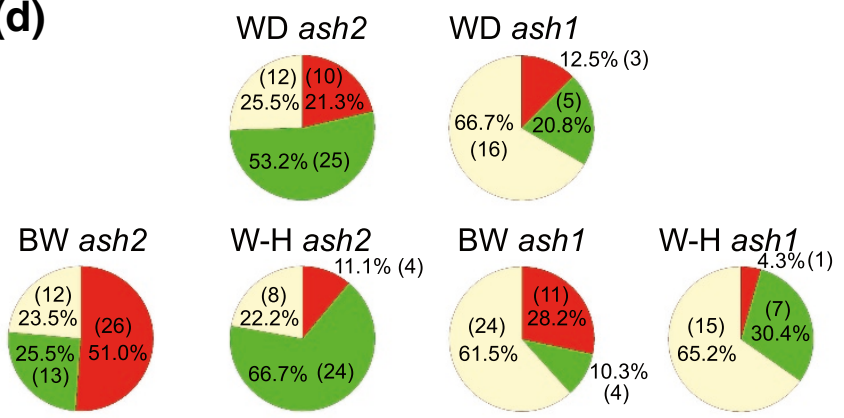

Figure 2 (see legend on next page) 
Figure 2 (see previous page)

Whole genome expression analysis of ash2 and ash I mutants. (a) GO annotation of genes that were upregulated (black bar) or downregulated (grey bar) in each allele (see text for details). The length of the bar indicates the fold change. $N$ indicates that no genes were found with a given term in this set. $O$ indicates over 10 times. An asterisk indicates FDR adjusted $p$ value $<0.01$ and a plus sign indicates $<0.05$ (FDR adjusted $p$ values for each GO annotation are detailed in Additional data file 2I); p.f., pattern formation. (b) Expression maps including all the genes belonging to GO terms 'Wing disc development', 'Anterior/posterior pattern formation, imaginal disc' and 'Dorsal/ventral pattern formation, imaginal disc'. All the genes from the array having these GO terms are represented irrespective of $\log _{2}$ ratios or $p$ values. Red indicates upregulation and green downregulation (see scale bar). (c) Semi-quantitative RT-PCR and microarray results for six genes. The height of the bar is proportional to the $\log _{2}$ ratio observed for each gene in the microarray or RT-PCR experiments in all three alleles. The expression level of all genes was statistically significant across microarray replicate experiments in all three mutant alleles $(p<0.05)$ except for ash2 in the ash 122 allele. Error bars represent standard error in microarray or semiquantitative RT-PCR analyses, respectively. (d) Comparison of genes that were upregulated or downregulated in ash2 and ash / mutants with the genes preferentially expressed in the wing disc (WD) according to Klebes et al. [37] and in the body wall (BW) and wing hinge (W-H) according to Butler et al. [38]. The full circle encompasses the total number of genes with valid $\log _{2}$ ratios in one or both of the ash2 alleles or in the ash $/$ allele for each comparison. The number of genes that were downregulated (green), upregulated (red) or showed no change in expression (yellow) over I.5 times in each comparison is shown in brackets.

phenotypes, indicating that the data obtained is reliable and that the functional relationship between ash 2 and ash1 found by genetic interactions [13] is maintained at the transcriptional level.

We found more underexpressed and fewer overexpressed genes with the terms 'development' and/or 'organ development' than expected by chance, supporting the view that trxG proteins are usually involved in maintaining the activated state of genes involved in such processes. For some of those genes (ash2, rpr, Act57B, wbl and ImpE2) we confirmed their change of expression by performing semi-quantitative RTPCR (Figure 2c). For others, like en or $v g$, we went one step further and analyzed their protein levels by immunohistochemistry and clonal analysis. In those genes, a correlation was observed between RNA expression and protein levels (Figure 3a,b). Some of the genes identified in this analysis may help to understand the mutant phenotypes observed, thereby establishing a link between the transcriptome and the phenotype.

\section{Wing development}

As expected based on the function of trxG genes, we found more downregulated genes belonging to the GO class 'wing disc development' than predicted by chance (Figure 2a,b). To identify other misregulated genes that might be involved in wing disc development despite not being annotated as such by GO, we compared our results with available microarray data listing genes predominantly expressed in the whole wing disc in comparison to leg disc [37] and in different parts (wing hinge or body wall) of the wing disc [38].

According to the functional GO annotation of the 67 wing disc-specific genes [37], the terms 'development', 'wing disc development' and 'transcription factor activity' rank amongst the top 10 statistically significant categories (Additional data file 17). Amongst these 67 genes, more were downregulated than upregulated in ash 2 and ash1 mutants (Figure 2d; Additional data file 18). These results support the GO classification of ash2 and ash1 transcriptomes and shows that the partial picture it provides is sufficient to classify results in a manner that enables successful comparison of transcriptomes beyond the gene to gene level. Regarding wing disc parts [38], there were more upregulated than downregulated genes that were related to the body wall in both ash 2 and ash1 mutants. In contrast, the number of downregulated wing-hinge genes was much greater than the number of upregulated genes (Figure 2d; Additional data file 18). These results suggest that ASH2 and ASH1 may play a more essential role in the wing hinge than in the body wall; this possibility is supported by the wing phenotypes (Figure $3 \mathrm{c}$ ) $[11,12]$ and the finding that more cell death is detected in the wing pouch in $a s h 2^{I 1}$ (Figure $3 \mathrm{e}$ ).

\section{Pattern formation}

Going downwards in the hierarchy of GO classification (Figure 2a), it is striking to find that genes that are downregulated in ash2 and/or ash1 mutants are enriched with 'dorsal/ventral pattern formation, imaginal disc' or 'anterior/posterior pattern formation, imaginal disc' annotations. With these annotations the differences are obvious and radical: no genes holding these descriptors are overexpressed in either ash2 or ash1 alleles. Again, all three alleles displayed similar patterns of misregulated genes (Figure 2b).

In the case of 'anterior/posterior pattern formation, imaginal disc', it is worth mentioning engrailed (en) and invected (inv), which are expressed in the posterior compartment of wing imaginal discs and are required to maintain its identity [39]. Although it was reported that En levels did not seem to be reduced in whole discs from other ash2 alleles [6], we show here that En/Inv levels are reduced in $a s h 2^{I 1}$ clones and that their pattern of expression is severely altered in whole $a s h 2^{I 1}$ discs (Figure 3a). An example of a downregulated gene in ash2 from the 'dorsal/ventral pattern formation, imaginal disc' class is Drop (Dr; Figure 2b). Absence of this gene leads, among other consequences, to a phenotype in which the dorsal wing margin bristles resemble the ventral ones [40]. A similar phenotype is observed in ash2 ${ }^{112411}$ adult wings (Figure $3 \mathrm{~d}$ ). The fact that en and $D r$ have putative PREs nearby [41] turns them into good candidates to be primary targets of PcG and trxG proteins. Furthermore, the rescue of wing pattern in general and the ventral wing margin bristles in particular upon overexpression of ash2 in an ash2 ${ }^{112411}$ mutant background (Figures 3c,d) highlights the importance of ash2 


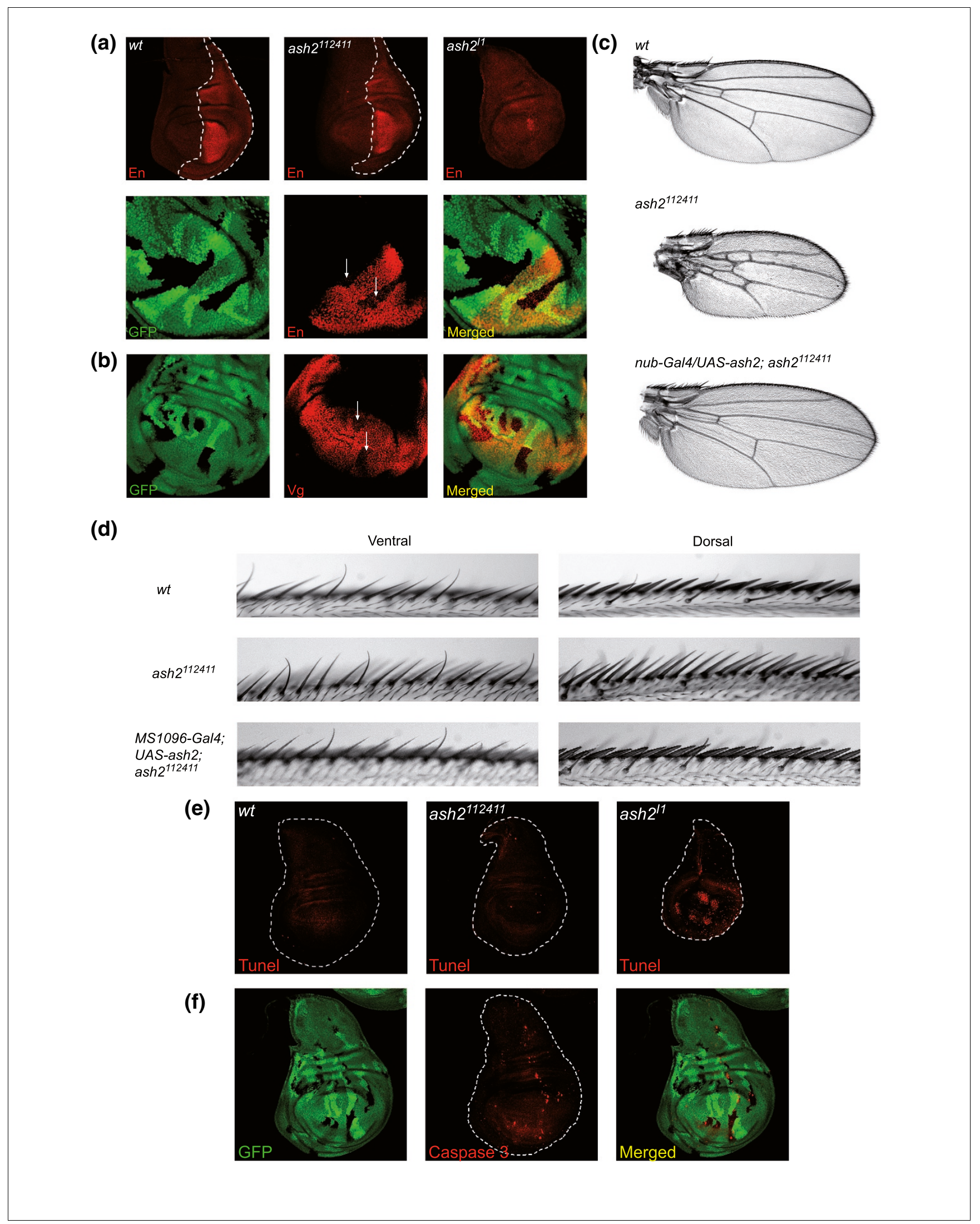

Figure 3 (see legend on next page) 
Figure 3 (see previous page)

Gene expression and phenotypes of ash2 mutants. (a) Engrailed (En) expression (dotted line) in wt and ash2 mutant wing discs (top panels). Reduction of En levels (white arrows) in ash2" homozygous cells (bottom panels). (b) Reduction of Vg levels (white arrows) in ash2" homozygous cells. (c) Wing phenotype of ash21124II homozygotes (central picture) is rescued to wt (top picture) by expression of ash2 in ash21124II homozygotes (bottom picture). (d) Dorsal bristles of the wing margin in ash211241। homozygotes are partially ventralized (compare central panels with upper panels). Dorsal bristles from ash2 1124II homozygotes are wt if ash2 is ectopically expressed with MS-1096-Gal4 driver (bottom panels). (e) Increased cell death in ash2"l homozygous wing discs in comparison to wt and ash211241। homozygous wing discs as seen by TUNEL staining (red). (f) Apoptosis in ash2" homozygous cells. Apoptotic cells are identified by staining with anti-cleaved Caspase 3 . In (a,b,f), wt cells are bright green, heterozygous cells are light green and ash $2^{\prime \prime}$ homozygous cells are black. In $(e, f)$, dotted lines outline the discs. In all wing discs, anterior is left and dorsal up.

in the positive regulation of genes involved in wing morphogenesis.

\section{Proliferation and apoptosis}

In a previous report, we showed that the expression level of genes involved in cell growth was altered in ash $2^{I 1}$ mutants [7]. We show here that this also holds true for ash1 mutants, since there are more downregulated and less upregulated genes annotated as 'regulation of growth' than expected by chance (Figure 2a). One of these downregulated genes in ash2 mutants is vestigial $(\mathrm{vg})$; vg is essential for wing development and no wings are formed in mutant flies due to extensive cell death $[42,43]$. The reduced Vg levels in cells lacking ash2 (Figure 3b) could explain the smaller size of ash2 mutant wings since $\mathrm{Vg}$ has been linked to cell survival and cell proliferation [44]. The gradient of downregulation observed for the $v g$ transcript in $a s h 2^{I 1}$, ash $2^{112411}$, and $a s h 1^{22}$ mutants (Figure 2b) matches well with the size differences observed in their mutant wing imaginal discs (Figure 1a). Ectopic expression of ASH2 in $a s h 2^{I 1}$ and $a s h 2^{112411}$ mutants increases the size of wing imaginal discs (data not shown) and wings (Figure 3c), demonstrating that the reduction in size is due to the absence of ASH2 or reduced levels of the protein. Although the detection of a PRE sequence near $v g$ supports $\mathrm{ASH} 2$ acting directly upon this gene, it cannot be ruled out that the combined weak downregulation observed in some of its regulatory proteins may also play a role. Other genes from the same class affected in ash2 mutants include Cyclin A (CycA), which has reduced protein levels in homozygous ash $2^{I 1}$ cells [7], and the growth promoter Cdk4 [45], a Cyclin D-interacting protein that displays the greatest reduction in expression amongst the 'regulation of growth' genes in $a s h 2^{I 1}$ wing discs.

The smaller size of wing discs and adult wings can be explained by a lack of growth and/or an enhancement of cell death. The levels of the pro-apoptotic gene reaper ( $r p r$ ) were increased in ash2 and ash1 mutants (Figure 2c), suggesting that cell death plays a role in the reduction of wing disc size. TUNEL assays on third instar larvae wing imaginal discs of ash $2^{I 1}$ and $a s h 2^{112411}$ showed a striking pattern in the former, where although dying cells could be found scattered around the whole disc, there was a high concentration of them in the prospective intervein regions of the wing pouch (Figure $3 \mathrm{e}$ ). This resembles the pattern observed upon DNA damageinduced cell death through irradiation [46] and suggests that genes involved in wing patterning might somehow influence the onset of cell death. Moreover, cleaved Caspase 3 was predominantly found in the wing pouch of $a s h 2^{I 1}$ wing imaginal discs (data not shown) and was highly restricted to ash ${ }^{I 1}$ homozygous cells, as revealed by clonal analysis (Figure $3 \mathrm{f}$ ). Taken together, these results indicate that ASH2 is essential for cell survival and to avoid apoptosis in some specific areas of the wing disc. In normal conditions, ASH2 may maintain activated states of transcription of specific intervein region genes that could themselves be anti-apoptotic or activators of other factors with this propriety.

In conclusion, the remarkable similarities between the transcriptomes of ash 2 and ash 1 seen by gene to gene comparisons, GO annotations and comparisons with other genomewide data strongly suggest that these two genes are closely related. However, differences between them are also observed. For example, the fact that they cannot substitute each other and that they do not display exactly the same phenotypes indicates that they may play singular and independent roles.

\section{ash2 mutants are enriched in mitochondrial and/or ribosomal genes similarly to Sin3A-deficient cells}

To gain insight into the specific functions of ash2 and ash1, we compared their expression profiles with those of other proteins that also act at the chromatin level. In a recent study, Affymetrix GeneChips were used to establish a relationship between dmyc and Polycomb (Pc) in Drosophila embryos [47]. Although PcG and trxG genes act upon some identical target genes in an antagonistic manner, we did not detect a significant overlap between the ash2 or ash1 and Pc sets of misregulated genes. We also compared our results with those obtained in larval null mutants of the Nurf3O1 subunit of the nucleosome remodeling factor complex NURF [48], and cells with reduced levels of Sin3A, a component of a multimeric histone deacetylase complex that includes $\operatorname{Rpd} 3$ [49]. While comparison of ash 2 and ash 1 transcriptomes with those from Nurf3O1 mutants did not reveal any significant overlap, intriguing coincidences were found when comparing ash2and $\operatorname{Sin} 3 A$-regulated genes.

The genes upregulated in S2 and Kc Drosophila cell lines with a Sin3A deficiency generated by RNA interference are enriched with GO annotations related to the mitochondrion [49] (Additional data file 19), a trend also observed in genes upregulated in ash2 mutants (Figure 2a; Additional data files 
6 and 10). The upregulation of genes related to mitochondria and/or ribosomes is not a general effect, since this is not observed in either the Pc and Nurf301 sets of misregulated genes $[47,48]$ or in other mutants analyzed with our microarrays (data not shown). In addition, a gene to gene comparison between the misregulated genes for $\operatorname{Sin} 3 A$ and those for ash2 indicated that many of them tend to change in the same direction (Figure 4a; Additional data file 20). One possibility could be that $\operatorname{Sin} 3 A$ or another subunit of the deacetylase complex is a target of ASH2. However, from the two core members of the complex (Sin3A and Rpd3), only a slight reduction in the levels of $\operatorname{Sin} 3 A$ is observed in the ash $2^{112411}$ mutant allele. Moreover, RT-PCR analysis in both ash2 mutants confirms that there are no major differences in $\operatorname{Sin}_{3} A$ expression levels (data not shown), suggesting that $\operatorname{Sin}_{3} A$ and $R p d 3$ are unlikely to be ASH2 target genes. Taking into account the important differences between these arrays (wing disc versus tissue culture cells and two-color microarray platform versus Affymetrix GeneChips), the large number of commonly regulated genes between the two analyses suggests a putative functional relationship between ASH2 and Sin3A.

\section{ASH2 and Sin3A interact with HCF and colocalize on polytene chromosomes}

In recent years, several studies in mammals have reported the presence of $\mathrm{ASH} 2$ in multimeric complexes homologous to the yeast Set1 complex that can methylate $\mathrm{H}_{3} \mathrm{~K}_{4}$ [21-26,50]. Strikingly, one variant of this activation-related complex is tethered together by HCF-1 with the Sin3/histone deacetylase (HDAC) complex. The latter is associated with repression activities and includes, amongst others, Sin3, RbAp48 and the Rpd3 homologues HDAC-1 and HDAC-2 [25].

To assess a putative physical interaction between ASH2 and Sin3A in Drosophila, we performed co-immunoprecipitation experiments in S2 cells and embryos and immunocytochemical detection of ASH2, Sin3A and HCF on salivary gland polytene chromosomes. As expected for proteins that regulate transcription, all three were located in the nucleus (Additional data file 24) and co-immunoprecipitation experiments demonstrated that HCF binds both Sin3A and ASH2 (Figure $4 \mathrm{~b}-\mathrm{d}$ ). The interaction between $\mathrm{HCF}$ and $\mathrm{ASH} 2$ is easily detected but the interaction between HCF and Sin3A is only visible by a faint band in the embryo extract. Moreover, the HCF-ASH2 interaction seems to be more stable than that of HCF-Sin3A, since the former resists more stringent conditions in terms of lysis buffer composition (see Materials and methods). Although we were not able to co-immunoprecipitate Sin3A and ASH2, we cannot rule out the possibility that they are tethered together by HCF, as occurs in their human counterparts [25]. Although this putative association of ASH2 and Sin3A through HCF might only happen in certain cell contexts, as previously suggested in humans [25], it is supported by the results of immunohistochemistry on polytene chromosomes showing that these proteins colocalize at several loci (Figure $5 \mathrm{a}, \mathrm{b})$. ASH2 binding patterns are highly coin- cident with those of Sin3A and HCF and all of them are nonoverlapping with DAPI counterstaining, with the exception of $\mathrm{HCF}$ at the chromocenter. Comparison of bands bound by Sin3A, HCF and ASH2 revealed that some sites are shared between all three (Figure $5 \mathrm{~b}$ ), suggesting the existence of a complex containing these proteins. Although it might seem surprising that proteins with opposite transcriptional outcomes might be found in the same complex, this is not an exception. For example, the trxG human Brahma nucleosome remodelling complex (hBrm) contains Sin3, HDAC-1, HDAC2 and RpAb48, all of them proteins from the human Sin3 histone deacetylase complex [51]. Furthermore, these four proteins and hBrm are also found in the ALL-1 (acute lymphoblastic leukemia - 1) complex, which exhibits chromatin remodeling and histone acetylation, deacetylation and methylation activities [52].

\section{ASH2 is required for trimethylation of $\mathrm{H} 3 \mathrm{~K} 4$}

Consistent with the $\mathrm{H}_{3} \mathrm{~K}_{4}$ methyltransferase activity reported for the Set1/ASH2 complex in humans [25], we found that ASH2 colocalizes on polytene chromosomes with trimethylated $\mathrm{H}_{3} \mathrm{~K}_{4}$ (Figure 6a). To gain insight into the molecular function of $\mathrm{ASH} 2$, we compared the levels of $\mathrm{H}_{3} \mathrm{~K}_{4}$ trimethylation in histones purified from $w t$ and $a s h 2^{I 1}$ mutant flies, respectively, by western blot (Figure 6b). The lack of ASH2 results in a dramatic reduction of $\mathrm{H}_{3} \mathrm{~K}_{4}$ trimethylation, indicating that $\mathrm{ASH} 2$ is involved in this modification. Analysis of $\mathrm{H}_{3} \mathrm{~K} 4$ trimethylation in vivo confirmed the results, since this epigenetic mark was below detectable levels in ash ${ }^{I 1}$ mutant clones (Figure 6c). The results presented here are the first obtained in Drosophila that show that ASH2 plays a role in the chromatin modification machinery. Although the nature of this regulation remains unclear, the fact that ASH2 does not have any known domain with histone methyltransferase activity suggests that it could be acting in a complex as a structural platform to facilitate the interaction between nucleosomes and proteins with enzymatic activity. This hypothesis is supported by the presence in ASH2 of a PHD domain, which has the ability to bind methylated lysines [53]. However, other proteins might act to recognize and present $\mathrm{H}_{3}$ in a similar way to human WDR5 $[54,55]$.

\section{Conclusion}

The evidence presented here suggests that, like in humans, Drosophila might harbor an $\mathrm{ASH} 2$ containing complex that could be tethered together with Sin3A by HCF. Although generally associated with opposite transcriptional activities, it has been proposed that these proteins may cooperate in transcriptional regulation [25]. The Sin3A complex is generally involved in transcriptional silencing, but in at least one case it is necessary for the activation of certain genes [56]. Rpd3 is also bound to active promoters in Drosophila [57], and in $S$. cerevisiae it is preferentially associated with promoters that direct high transcriptional activity [58]. Likewise, it is feasible that canonical positive regulators such as ASH2 may also play 
(a)

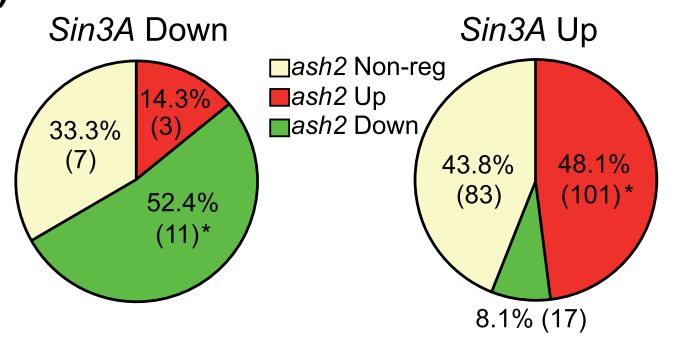

(c)

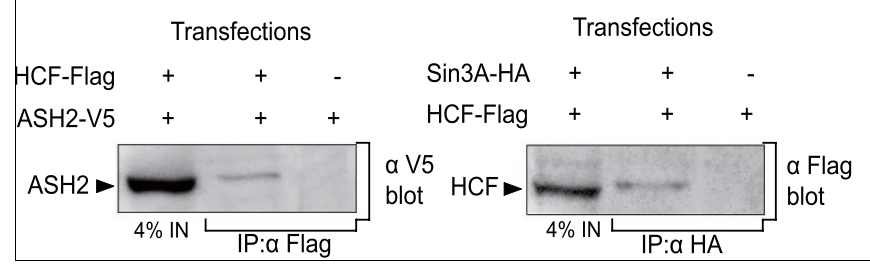

(b)

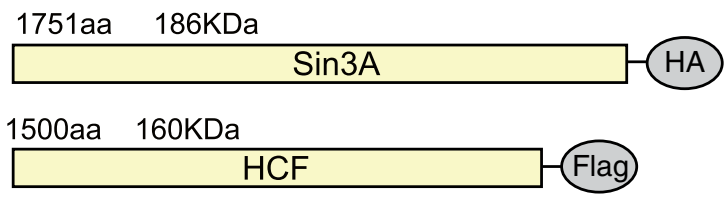

556aa 63KDa

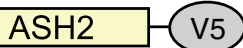

(d)

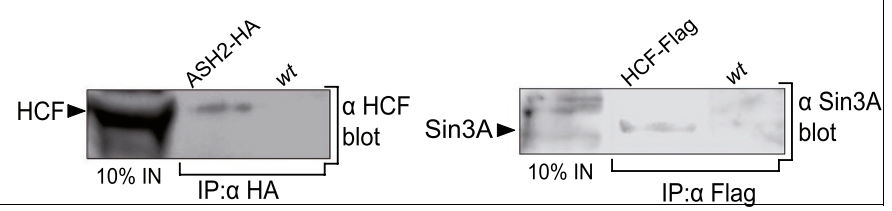

Figure 4

Functional and physical interaction between ASH2 and Sin3A mediated by HCF. (a) ASH2 and Sin3A mutants share a large number of commonly misregulated genes. Each full circle encompasses the total number of genes that are downregulated (left) or upregulated (right) in Sin $3 A$-deficient cells (according to Pile et al. [43]) and have valid $\log _{2}$ ratios in one or both of the ash2 alleles. The number of genes that are downregulated (green), upregulated (red) or do not display altered expression (yellow) over I.5 times in one or both of the ash2 alleles is shown in brackets. An asterisk indicates statistically significant overlap: $p=1.06 \times 10^{-4}$ (left), $p=5.88 \times 10^{-32}$ (right). (b) Diagram showing Sin3A-HA, HCF-Flag and ASH2-V5 fusion proteins. The number of amino acids and the predicted molecular weight without counting tags are indicated above each construct. (c) HCF interacts with ASH2 and Sin $3 \mathrm{~A}$ in S2 cells. Anti-Flag immunoprecipitations were performed using cells expressing HCF-Flag and ASH2-V5, or ASH2-V5 alone as a negative control, and immunoblotted with anti-V5 (left). Anti-HA immunoprecipitations were performed with S2 cells transfected with Sin3-HA and HCF-Flag, or HCF-Flag alone as a negative control, and immunoblotted with anti-Flag (right). Input lane shows $4 \%$ of the total extract volume used for co-immunoprecipitations. (d) HCF interacts with ASH2 and Sin3A in embryos. Co-immunoprecipitation experiments were performed in transgenic embryos overexpressing ASH2HA (left) or HCF-Flag (right) with daughterless-gal4. wt embryos were used as a negative control. Input lane shows $10 \%$ of the total extract volume used for co-immunoprecipitations.

a role as negative regulators in certain contexts, and finding so many upregulated genes related to mitochondria in ash2 mutants makes this idea attractive. An appealing hypothesis to explain the existence of positive and negative regulators of chromatin remodeling in the same complex is that they could be necessary to maintain an equilibrium between the different histone modifications and to rapidly switch between activated or repressed states of transcription. Alternatively, the activities of these complexes are perhaps sequential, since some deacetylation seems to be required to enable histone methylation [59]. Another explanation for the coexistence of different modifying activities is that they could be targeted to transcription factors, as occurs with the Drosophila T-cell factor, which can be repressed by acetylation driven by dCBP, a protein that, paradoxically, acts as a co-activator of other transcription factors [6o]. For example, dCBP interacts and colocalizes with ASH1 on polytene chromosomes [61] and is also found with Trithorax (Trx) in the activating TAC1 acetylation complex [62]. Those observations have further implications since ash1 and trx, together with ash2, were found to be functionally related [63] and several other lines of evidence point in the same direction. ASH1 and Trx co-immunoprecipitate in embryonic extracts and colocalize on polytene chromosomes [64], and accumulation of Trx is reduced on ash1 mutant polytene chromosomes [65]. ASH1 is an
$\mathrm{H}_{3} \mathrm{~K}_{4}, \mathrm{H}_{3} \mathrm{~K} 9$ and $\mathrm{H}_{4} \mathrm{~K} 2 \mathrm{O}$ histone methyltransferase [27,28] and $\mathrm{H}_{3} \mathrm{~K}_{4}$ dimethylation is severely reduced in ash1-mutant polytene chromosomes but only mildly in ash2-mutant chromosomes [28].

Byrd and Shearn [28] proposed a model to explain the coordinated action of the ASH1, Trx and ASH2 proteins. In that model, ASH1 and Trx would be required to acetylate and mono- and/or dimethylate histones, and a putative Set1ASH2 complex would be involved in subsequent $\mathrm{H}_{3} \mathrm{~K}_{4}$ methylations. This hypothesis is strongly supported by the demonstration that the yeast and human ASH2 homologues are essential for $\mathrm{H}_{3} \mathrm{~K}_{4}$ trimethylation but not for mono- or dimethylation [26,66,67]. In addition, ASH2 accumulation is reduced on ash1-mutant polytene chromosomes but in the reverse situation ASH1 accumulation is not reduced on ash2mutant chromosomes [17], indicating that ASH2 needs ASH1 or its activity to be recruited. Our results also support this model. Firstly, the expression profiles from ash2 and ash1 mutant alleles reveal that they are highly coincident at both the gene to gene and functional levels, indicating a functional relationship between them. Secondly, the results from coimmunoprecipitation assays, immunolocalization on polytene chromosomes and the reduction of $\mathrm{H}_{3} \mathrm{~K}_{4}$ trimethylation in $\operatorname{ash}^{I 1}$ mutant cells suggest the existence of a Set1- 
(a)
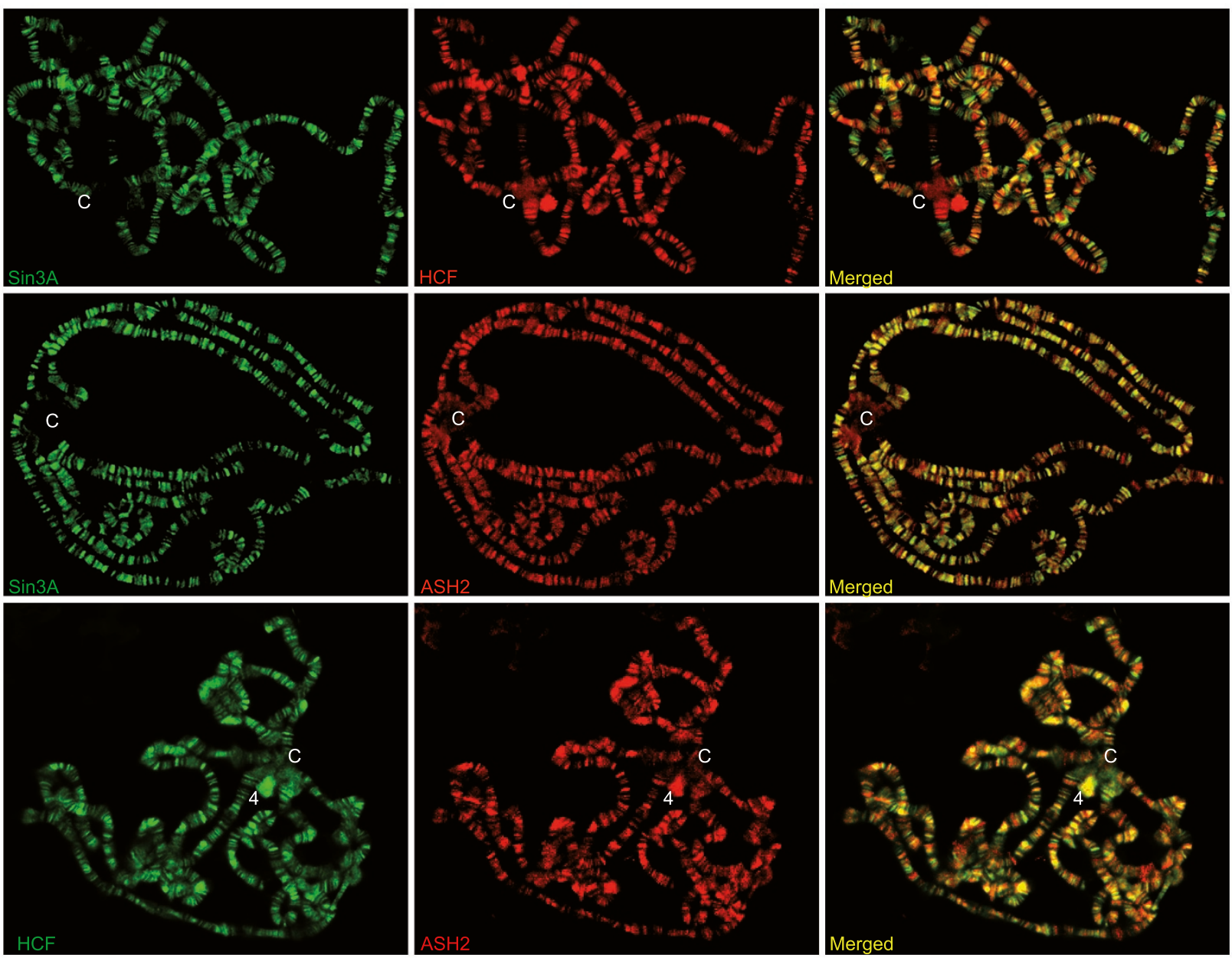

1

(b)

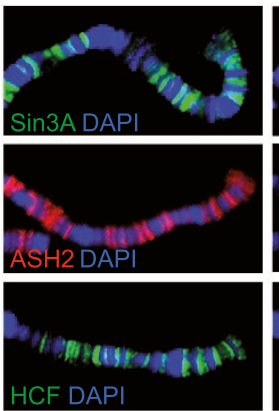

2

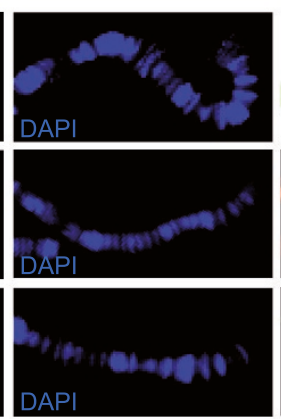

3

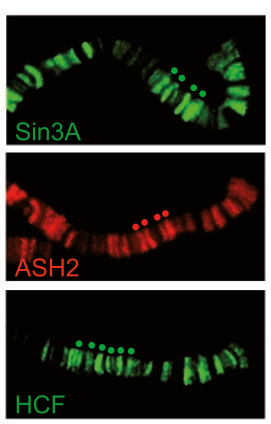

4

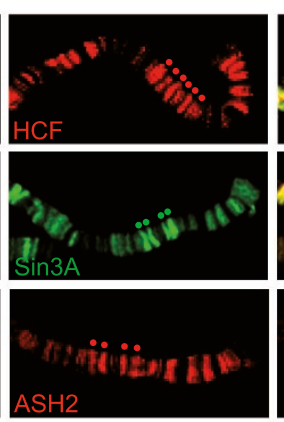

5

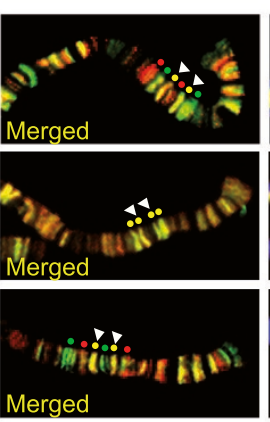

6

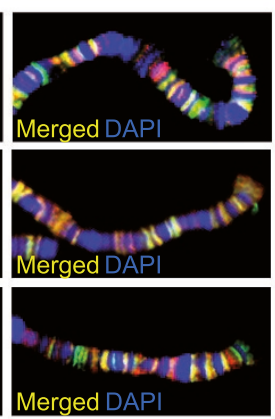

Figure 5

Immunodetection of ASH2, Sin3A and HCF on polytene chromosomes. (a) Images of all the chromosomes showing partial colocalization of Sin3A and HCF (top panel), Sin $3 \mathrm{~A}$ and ASH2 (central panel), and HCF and ASH2 (bottom panel). Note that only HCF is found in the chromocenter (C) and that no $\operatorname{Sin} 3 \mathrm{~A}$ is detected in chromosome 4 (4). (b) Details of the $2 \mathrm{~L}$ chromosome arm. Sin $3 \mathrm{~A}, \mathrm{ASH} 2$ and HCF staining does not overlap with DAPI (columns I3). Sin $3 \mathrm{~A}$ and HCF (top panel), ASH2 and Sin $3 \mathrm{~A}$ (central panel), and HCF and ASH2 (bottom panel) colocalize at many sites (columns 3-5). Green and red dots in columns 3-4 indicate strongly stained sites. Green and red dots in column 5 indicate a weak colocalization (more green staining or more red staining) and yellow dots indicate bands with strong colocalization. Arrowheads indicate sites of triple colocalization between ASH2, HCF and Sin $3 \mathrm{~A}$. Antibodies used were anti-Sin3A, anti-HCF and anti-HA (for ASH2-HA detection). 
(a)
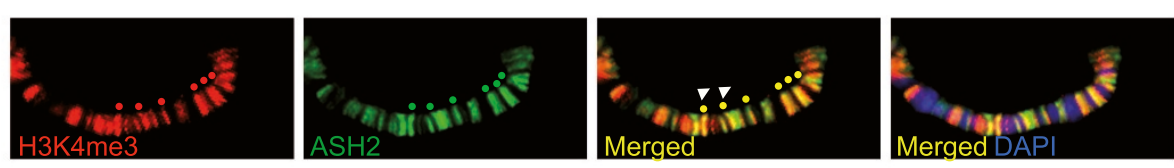

(b)

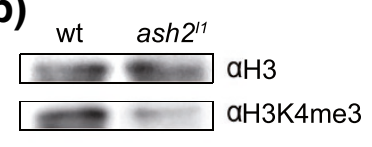

(c)
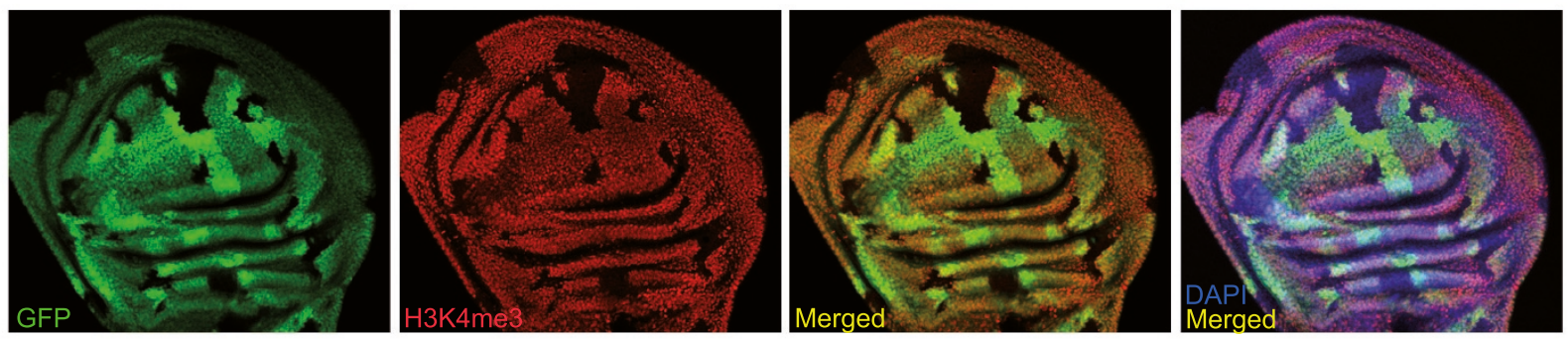

\section{Figure 6}

$\mathrm{H} 3 \mathrm{~K} 4$ trimethylation is severely reduced in ash2" ${ }^{\prime \prime}$ mutants. (a) Colocalization of trimethylated $\mathrm{H} 3 \mathrm{~K} 4$ (red) with ASH2 (green) in the polytene chromosome $2 \mathrm{~L}$ arm. (b) Detection by western blot of $\mathrm{H} 3 \mathrm{~K} 4$ trimethylation on wt and ash2"l histone extracts. $\mathrm{H} 3$ was used as a loading control. (c) Detection of $\mathrm{H} 3 \mathrm{~K} 4$ trimethylation (red) in wt (bright green), heterozygous (green) and ash2" homozygous (black) wing disc cells. Note that in the latter cells H3K4 trimethylation is severely reduced. Antibodies used were anti-HA (for ASH2-HA detection), anti-trimethylated H3K4 and anti-H3. Nuclei are labelled with DAPI (blue).

ASH2 complex in Drosophila involved in $\mathrm{H}_{3} \mathrm{~K}_{4}$ trimethylation, filling a gap in the proposed model. Finally, since HCF interacts with both ASH2 and Sin3A, it is tempting to speculate that, in Drosophila, these proteins could also be subunits of multimeric complexes similar to those found in mammals. However, the fact that the genes in common between ash2 and ash1 mutants differ from those that are common between ash2 mutants and Sin $3 A$-defficient cells suggests that different processes such as pattern formation, development or general metabolism may be regulated by ASH2 upon its association with distinct complexes.

\section{Materials and methods Drosophila strains}

All Drosophila strains and crosses were kept on standard media with $0.025 \%$ bromophenol blue at $25^{\circ} \mathrm{C}$. The reference line used in all cases was the $w^{1118} ;+;+$ isogenic line from the DrosDel Collection [68]. To reduce the differences in the biological background between the alleles under study and the reference strain, we transferred chromosomes $\mathrm{X}, \mathrm{Y}$ and 2 from the isogenic line to the TM6c-balanced $a s h 2^{I 1}$, ash $2^{112411}$ and $a s h 1^{22}$ alleles. The latter was provided by A Shearn and was studied in homozygosis by combining it with ash $1^{22} \mathrm{~F} 2 \mathrm{~A}$, a kind gift from J Muller [29].

To generate UAS-ash2 transgenic flies, full-length ash2- $R C$ and three copies of the HA (hemagglutinin) epitope were cloned between the EcoRI and NotI sites of the pUAST plasmid [69]. To generate UAS- $H C F$ transgenic flies, full-length $H C F-R C$ amplified from the pACXT-T7- $H C F$-Flag (kindly provided by A Wilson [70]) was introduced between the NotI and KpnI sites of the pUAST plasmid [69]. MS1096-Gal4 and $n u b-G a l 4$ drivers were used for rescue experiments, sgs3-
Gal4 and $A c t 5 C$-Gal4 for polytene chromosome immunolocalization and $d a-G a l 4$ for co-immunoprecipitation experiments in embryos.

\section{Two-color microarray production, sample preparation and hybridization}

Microarrays were printed on Corning UltraGAPS slides (Corning, NY, USA) at the Plataforma de Transcriptòmica (SCT-PCB, Universitat de Barcelona, Spain) using the Drosophila Genome Oligo Set version 1.1 (Operon Biotechnologies Inc., Huntsville, AL, USA), a collection of 14,593 probes representing 13,577 Drosophila genes with Flybase ID. The 70mer Arabidopsis sequences from TIGR [71] and spots with no material or with buffer were also printed to be used as spike-in and negative controls, respectively. The microarray annotation is deposited in the Gene Expression Omnibus (GEO) database [35,36] with number GPL3797.

Wandering blue-gut staged $\mathrm{Tb}+$ early third instar larvae were selected in all cases to extract total RNA from wing discs using the RNeasy Protect Mini Kit (Qiagen Inc., Valencia, CA, USA). At least two independent total RNA extractions were carried out from wing imaginal discs for $w^{1118} ;+; a s h 2^{I 1}$, $w^{1118} ;+; a s h 2^{112411}, w^{1118} ;+; a s h 1^{22} / a s h 1^{22} \mathrm{~F} 2 \mathrm{~A}$ and $w^{1118} ;+;+$ strains. Quality was assessed in all samples using the Eukaryote Total RNA Nano Assay on a 2100 Bioanalyzer (Agilent Technologies Inc., Santa Clara, CA, USA). Total RNA from $w^{1118}$;+;+ wing imaginal discs was pooled and used as a common reference against $a s h 2^{I 1}$, ash $2^{112411}$ and $a s h 1^{22} /$ $a s h 1^{22}$ F2A. Four microarrays were hybridized for each experiment in biological replicate pairs, such that the total RNA from the sample used as a starting material came from different extractions. Both arrays from each pair were hybridized with the same amplified RNA from sample and common ref- 
erence (obtained using the Amino-Allyl Messageamp II aRNA Amplification Kit from Ambion Inc., Austin, TX, USA) but with dyes Cy3 and Cy5 (GE Healthcare UK Ltd, Buckinghamshire, UK) swapped to take dye-bias into account.

\section{Two-color microarray analysis and data mining}

GenePix Results (GPR) data files were obtained for each microarray with an Axon 400oB scanner and GenePix Pro 6 (Molecular Devices Corp., Sunnyvale, CA, USA). All GPR files were analyzed with the Limma package from BioConductor [72,73] using the same criteria. The spots not fulfilling the quality thresholds (based on spot size, foreground versus background signals, saturation, coincidence between differently calculated ratio measures and $\mathrm{R}^{2}$ of regression ratio) were eliminated from the analysis, and the data were background corrected with the normexp method and normalized using OLIN [74]. Between-array normalization was carried out independently for each set of four arrays using the mad method from OLIN, and a linear model was fitted and corrected with False Discovery Rate (FDR) [72]. We obtained lists of genes that were differentially expressed (had an FDRcorrected $p$ value of less than 0.05 and at least two spots from the four replicate arrays that passed the quality filters) over 1.5- or 2.0-fold in the mutants compared to the reference strain.

A script was written to collect all GO terms for each gene on the array and to assess whether they are enriched with regulated genes by using a hypergeometric distribution. $P$ values of each term are adjusted with the FDR procedure [75] to correct for multiple testing. The output from that script can be used as input for another one that draws pie charts (available at [76]). Calculations of the statistical significance of the number of overlapping genes between different sets were also corrected for multiple testing in a similar way.

\section{Affymetrix array analysis}

Two Affymetrix GeneChip Drosophila Genome 2.0 arrays (Affymetrix Inc.) were hybridized at the Unitat de Genòmica (IDIBAPS, Barcelona, Spain) with amplified RNA from wing imaginal discs of either $a s h 2^{I 1}$ or the common reference. Analysis was performed with the Affymetrix GeneChip Operating Software (GCOS) and only spots called 'Present' (detectable expression) were taken into account for calculation of Pearson's correlation coefficients. The number of spots involved in each pairwise comparison in Figure $1 \mathrm{~b}$ (from left to right and top to bottom) were $7,817,7,170,6,147,9,051$ and 6,436 .

\section{Semi-quantitative RT-PCR}

Reverse transcription reactions with independently extracted RNA from all mutant alleles and the reference were used to synthesize cDNA with Superscript III (Invitrogen Corp., Carlsbad, CA, USA) according to the manufacturer's instructions. One microliter of each RT reaction was used in each PCR reaction, in which the test and the reference gene
( $m R p L 9)$ were amplified together. Samples from 22, 26, 30 and 34 cycles were run on $2 \%$ agarose gels to estimate saturating conditions. Samples with two discrete non-saturated bands were quantified using a DNA 1000 Assay in a 2100 Bioanalyzer (Agilent Technologies Inc., Santa Clara, CA, USA). Expression values of test genes were normalized using the reference gene. Four measures were taken for each gene to evaluate standard error.

\section{Clonal analysis, immunohistochemistry and TUNEL assay}

Clones were generated at $52 \pm 6$ hours after egg lay by FLP (Flipase)-mediated mitotic recombination [77] with a 30 minute heat shock at $37^{\circ} \mathrm{C}$. Immunohistochemistry was performed according to standard protocols with the primary antibodies mouse 4D9 anti-En/Inv (Developmental Studies Hybridoma Bank, University of Iowa, IA, USA), rabbit antiVg (kindly provided by S Carroll), rabbit anti-cleaved Caspase 3 (Cell Signalling Technology Inc., Danvers, MA, USA) and rabbit anti-trimethyl $\mathrm{H}_{3} \mathrm{~K}_{4}$ (Abcam Inc., Cambridge, MA, USA) used at concentrations of 1:10, 1:20,1:100 and 1:200, respectively. Rhodamine Red-conjugated secondary antibodies were from Jackson ImmunoResearch Laboratories (West Grove, PA, USA). Dying cells were detected by TUNEL assay, labeling DNA 3 '-OH ends with Chromatide BODIPY Texas Red-14-dUTP (Invitrogen Corp.) for 1.5 hours at $37^{\circ} \mathrm{C}$ with terminal deoxynucleotidyl transferase (Roche Diagnostics, Indianapolis, IN, USA). In all cases, the discs were mounted in Slowfade Light Antifade (Invitrogen Corp.) and images collected using a Leica TCS 4D confocal laser scanning microscope.

\section{Constructs, cellular localization, co- immunoprecipitation assays and western blot}

$\mathrm{S} 2$ cells were maintained at $25^{\circ} \mathrm{C}$ in Drosophila Schneider's medium containing $10 \%$ fetal bovine serum and $1 \%$ penicillin/streptomycin (Invitrogen Corp.). Cells were transfected with Effectene (Qiagen Inc.), according to the manufacturer's protocol and collected 48 hours later. Three different constructs were used containing full-length coding regions of either ash2, Sin3A or HCF. pAc5.1-ash2-V5-His A was produced by inserting ash2, obtained from the Berkeley Drosophila Genome Project clone LD31680, into pAc5.1-V5-His A (Invitrogen Corp.). pAc5.1-Sin $3 A$-HA-His B was produced by inserting $\operatorname{Sin} 3 A$, obtained from the p3NB-Sin $3 A$ plasmid provided by D Pauli [78], into a pAc5.1- $\mathrm{V}_{5}$-His B in which $\mathrm{V}_{5}$ was substituted for HA.

For immunofluorescence analysis, transfected S2 cells were plated onto coverslips previously coated with $0.5 \mathrm{mg} / \mathrm{ml}$ concanavalin A for 1 hour and fixed with 4\% paraformaldehyde. The antibodies used were as follows: rabbit anti-V5 (1:1,00o; Sigma-Aldrich Corp., St Louis, MO, USA), mouse anti-HA (1:200; Roche Diagnostics), rabbit anti-Flag (1:100; SigmaAldrich Corp.), donkey anti-rabbit FITC (1:400; Jackson ImmunoResearch Laboratories), and goat anti-mouse FITC 
(1:400; Jackson ImmunoResearch Laboratories). Rhodamine phalloidin (Invitrogen Corp.) was used at a dilution of 1:40. Cell nuclei were stained with DAPI. Cells were mounted in Mowiol-Dabco and visualized under a Leica spectral microscope.

For co-immunoprecipitation assays, cells were washed twice with cold phosphate-buffered saline and lysed and disrupted by freezing and thawing cycles. For anti-Flag immunoprecipitation, the lysis buffer was $50 \mathrm{mM}$ Tris $\mathrm{HCl}$, $\mathrm{pH} 7.4,150 \mathrm{mM} \mathrm{NaCl}, 1 \mathrm{mM}$ EDTA, $1 \%$ Triton X-100 + complete protease inhibitors (Roche Diagnostics). The whole-cell extract was pre-cleared for 1 hour at $4^{\circ} \mathrm{C}$ with protein ASepharose and incubated with $40 \mu \mathrm{l}$ of equilibrated EZview Red anti-Flag M2 AffinityGel beads (Sigma-Aldrich Corp.) for at least 3 hours at $4^{\circ} \mathrm{C}$. The immunoprecipitates were washed three times for 15 minutes in lysis buffer (in the second wash the concentration of $\mathrm{NaCl}$ was increased to $300 \mathrm{mM}$ ) and eluted by boiling in loading buffer containing SDS. For antiHA immunoprecipitations, we used the protocol described above with the following modifications: cells were lysed and washed in $20 \mathrm{mM}$ HEPES, pH 7.9, 20\% glycerol, $100 \mathrm{mM}$ $\mathrm{NaCl}, 0.2 \mathrm{mM}$ EDTA, $0.1 \% \mathrm{NP}-40$ + complete protease inhibitors and cell extracts were incubated without pre-clearing with $75 \mu \mathrm{l}$ of anti-HA affinity matrix (Roche Diagnostics). For co-immunoprecipitation experiments from embryo extracts, o-16 h embryos were dechorionated and rinsed extensively, incubated with $50 \mathrm{mM}$ Tris $\mathrm{pH} 8,200 \mathrm{mM} \mathrm{NaCl}, 5 \mathrm{mM}$ EDTA, $0.5 \% \mathrm{NP} 40$ + complete protease inhibitors, homogenized and centrifuged. The supernatant was collected, sonicated and mixed with $40 \mu \mathrm{l}$ of EZview Red anti-Flag M2 AffinityGel beads or anti-HA affinity matrix to perform the co-immunoprecipitation experiments as described above. In all cases, samples were run on $7 \cdot 5-10 \%$ SDS-PAGE gels and transferred to PVDF membranes. The following antibodies from Sigma-Aldrich Corp. were used for western blots: rabbit anti-V5 (1:2,00o), rabbit anti-Flag (1:400), sheep anti-mouse peroxidase $(1: 3,000)$ and goat anti-rabbit peroxidase (1:3,000). The mouse anti-HA (1:1,000) was from Roche Diagnostics and rabbit anti-Sin3A (1:500) and rabbit antiHCF (1:5,00o) were kindly provided by D Wassarman and J Workman, respectively. Proteins were detected with the EZL system (Biological Industries Ltd., Kibbutz Beit Haemek, Israel).

To compare the levels of trimethylated $\mathrm{H}_{3} \mathrm{~K}_{4}$ between $w t$ and ash $2^{I 1}$ larvae, histones were obtained by acidic extraction, dialyzed and separated on $15 \%$ SDS-PAGE gels. Immunoblots were performed with anti-H3 (1:2,00o) and anti-trimethyl $\mathrm{H}_{3} \mathrm{~K}_{4}$ (1:5,000) antibodies (Abcam Inc.).

\section{Staining of polytene chromosomes}

Salivary glands of $w t$ and UAS-ash2 transgenic flies were dissected in Gohen buffer, fixed for 2 minutes and transferred to a solution with acetic acid and formaldehyde for 3 minutes before squashing to spread the polytene chromosomes. Stain- ing was performed by $\mathrm{O} / \mathrm{N}$ incubation at $4^{\circ} \mathrm{C}$ with the following antibodies: mouse anti-HA (1:200), rabbit anti-Sin3A (1:100), rat anti-HCF (1:50) and rabbit anti-trimethyl $\mathrm{H}_{3} \mathrm{~K}_{4}$ (1:200). FITC- or rhodamine red-conjugated secondary antibodies (1:200) were obtained from Jackson ImmunoResearch Laboratories and preparations were mounted with Mowiol-DAPI to stain the DNA. Chromosomes were visualized under a Leica microscope.

\section{Additional data files}

The following additional data are available with the online version of this paper. Additional data file 1 is a table listing the number of unique genes up- and downregulated over 1.5-fold $\left(\log _{2}\right.$ ratio $\left.=0.58\right)$ or 2.0 -fold $\left(\log _{2}\right.$ ratio $\left.=1\right)$ in each mutant allele. Additional data files 2, 3 and 4 are tables listing the genes downregulated and upregulated over 1.5- and 2.0-fold in $a s h 2^{I 1}$, ash $2^{112411}$ and $a s h 1^{22}$, respectively. Additional data files 5, 9 and 13 are tables containing the GO annotations of the genes downregulated over 1.5 -fold in $a s h 2^{I 1}$, ash2 $2^{112411}$ and ash $1^{22}$, respectively. Additional data files 6, 10 and 14 are tables containing the GO annotation of the genes upregulated over 1.5 -fold in $a s h 2^{I 1}$, ash2 $2^{112411}$ and $a s h 1^{22}$, respectively. Additional data files 7, 11 and 15 are tables containing the GO annotation of the genes downregulated over 2.0-fold in $a s h 2^{I 1}$, ash $2^{112411}$ and $a s h 1^{22}$, respectively. Additional data files 8, 12 and 16 are tables containing the GO annotations of the genes upregulated over 2.0-fold in $a s h 2^{I 1}$, ash2 $2^{112411}$ and $a s h 1^{22}$, respectively. Additional data file 17 is a table containing the GO annotations of wing disc genes identified by Klebes et al. [37]. Additional data file 18 is a table listing the genes misregulated in ash2 and ash1 mutants preferentially expressed in the wing disc and in the prospective wing-hinge or body wall region. Additional data file 19 is a table containing the GO annotations of the genes upregulated in $\operatorname{Sin} 3 A$ deficient cells according to Pile et al. [49]. Additional data file 20 is a table listing the genes misregulated in $\operatorname{Sin} 3 A$ deficient cells that are also misexpressed in ash2 and/or ash1 mutants. Additional data file 21 is a table containing the FDR adjusted $p$ values for the GO terms displayed in Figure 2a. Additional data file 22 is a figure containing pie charts showing the distribution of regulated genes in Molecular function GO classes. Additional data file 23 is a figure containing pie charts showing the distribution of regulated genes in Biological process GO classes. Additional data file 24 is a figure showing that $\mathrm{ASH} 2, \mathrm{HCF}$ and Sin3A are found in the nucleus.

\section{Acknowledgements}

We thank A Shearn and J Müller for ash I alleles, AC Wilson for the pAcXTT7-HCF-Flag construct, D Pauli for Sin3A-containing clones, D Wassarman for the anti-Sin3A antibody, The National Heart Lung and Blood Institute and the Program for Genomic Applications at The Institute for Genomic Research for providing us with $A$. thaliana spike-in controls, J Workman for the anti-HCF antibody, S Carrol for the anti-VG antibody, the Developmental Studies Hybridoma Bank for the anti-En/Inv antibody and the Instituto Nacional de Bioinformática, Spain, for analysis support. We are grateful to J Font, F Azorin and E Fuentes for help with polytene chromosome immunolocalizations and histone western blots, L Sevilla and A Punset for their 
help with microarray experiments, G Marfany, N Cols and N Agell for advice on cloning strategies and help with immunoprecipitation experiments, and R Guigó for insightful discussions. S Beltran and M Angulo were supported by fellowships from the Ministerio de Educación y Ciencia (MEC), Spain, and Universitat de Barcelona, respectively. M Pignatelli acknowledges a Juan de la Cierva postdoctoral contract. This project was supported by grants GEN200I-4846-C05-02 and BMC2003-05018 from MEC, Spain.

\section{References}

I. Dejardin J, Cavalli G: Epigenetic inheritance of chromatin states mediated by Polycomb and trithorax group proteins in Drosophila. Prog Mol Subcell Biol 2005, 38:3I-63.

2. Orlando V: Polycomb, epigenomes, and control of cell identity. Cell 2003, I I 2:599-606.

3. Ringrose L, Paro R: Epigenetic regulation of cellular memory by the Polycomb and Trithorax group proteins. Annu Rev Genet 2004, 38:413-443.

4. Ingham PW: Differential expression of bithorax complex genes in the absence of the extra sex combs and trithorax genes. Nature 1983, 306:591-593.

5. Kennison JA: The Polycomb and trithorax group proteins of Drosophila: trans-regulators of homeotic gene function. Annu Rev Genet 1995, 29:289-303.

6. Lajeunesse D, Shearn A: Trans-regulation of thoracic homeotic selector genes of the Antennapedia and bithorax complexes by the trithorax group genes: absent, small, and homeotic discs I and 2. Mech Dev 1995, 53:123-139.

7. Beltran S, Blanco E, Serras F, Perez-Villamil B, Guigo R, Artavanis-Tsakonas S, Corominas M: Transcriptional network controlled by the trithorax-group gene ash2 in Drosophila melanogaster. Proc Natl Acad Sci USA 2003, 100:3293-3298.

8. Collins RT, Treisman JE: Osa-containing Brahma chromatin remodeling complexes are required for the repression of wingless target genes. Genes Dev 2000, I4:3/40-3I52.

9. Smith ST, Petruk S, Sedkov Y, Cho E, Tillib S, Canaani E, Mazo A: Modulation of heat shock gene expression by the TACI chromatin-modifying complex. Nat Cell Biol 2004, 6:162-167.

10. Shearn A, Rice T, Garen A, Gehring W: Imaginal disc abnormalities in lethal mutants of Drosophila. Proc Natl Acad Sci USA I97I, 68:2594-2598.

11. Amoros M, Corominas M, Deak P, Serras F: The ash2 gene is involved in Drosophila wing development. Int J Dev Biol 2002, 46:32I-324.

12. Angulo M, Corominas M, Serras F: Activation and repression activities of ash2 in Drosophila wing imaginal discs. Development 2004, I 3 I:4943-4953.

13. Shearn A, Hersperger E, Hersperger E: Genetic studies of mutations at two loci of Drosophila melanogaster which cause a wide variety of homeotic transformations. Roux's Arch Dev Biol 1987, | 196:231-242.

14. Otte AP, Kwaks TH: Gene repression by Polycomb group protein complexes: a distinct complex for every occasion? Curr Opin Genet Dev 2003, 13:448-454.

15. Muller J, Hart CM, Francis NJ, Vargas ML, Sengupta A, Wild B, Miller EL, O'Connor MB, Kingston RE, Simon JA: Histone methyltransferase activity of a Drosophila Polycomb group repressor complex. Cell 2002, I I I:197-208.

16. Papoulas O, Beek SJ, Moseley SL, McCallum CM, Sarte M, Shearn A, Tamkun JW: The Drosophila trithorax group proteins BRM, ASHI and $A S_{2} 2$ are subunits of distinct protein complexes. Development 1998, I 25:3955-3966.

17. Cheng MK, Shearn A: The direct interaction between ASH2, a Drosophila trithorax group protein, and SKTL, a nuclear phosphatidylinositol 4-phosphate 5-kinase, implies a role for phosphatidylinositol 4,5-bisphosphate in maintaining transcriptionally active chromatin. Genetics 2004, 167:12/3-1223.

18. Nagy PL, Griesenbeck J, Kornberg RD, Cleary ML: A trithoraxgroup complex purified from Saccharomyces cerevisiae is required for methylation of histone H3. Proc Natl Acad Sci USA 2002, 99:90-94

19. Roguev A, Schaft D, Shevchenko A, Pijnappel WW, Wilm M, Aasland R, Stewart AF: The Saccharomyces cerevisiae Setl complex includes an Ash 2 homologue and methylates histone 3 lysine 4. EMBO J 200I, 20:7|37-7|48.
20. Miller T, Krogan NJ, Dover J, Erdjument-Bromage H, Tempst P, Johnston M, Greenblatt JF, Shilatifard A: COMPASS: a complex of proteins associated with a trithorax-related SET domain protein. Proc Natl Acad Sci USA 200 I, 98:12902-I 2907.

21. Lee JH, Skalnik DG: CpG-binding protein (CXXC finger protein I) is a component of the mammalian Setl histone H3-Lys4 methyltransferase complex, the analogue of the yeast Set I/ COMPASS complex. J Biol Chem 2005, 280:4I725-4173I.

22. Goo YH, Sohn YC, Kim DH, Kim SW, Kang MJ, Jung DJ, Kwak E, Barlev NA, Berger SL, Chow VT, et al: Activating signal cointegrator 2 belongs to a novel steady-state complex that contains a subset of trithorax group proteins. Mol Cell Biol 2003, 23:140-I 49.

23. Hughes CM, Rozenblatt-Rosen O, Milne TA, Copeland TD, Levine SS, Lee JC, Hayes DN, Shanmugam KS, Bhattacharjee A, Biondi CA, et al.: Menin associates with a trithorax family histone methyltransferase complex and with the hoxc8 locus. Mol Cell 2004, I 3:587-597.

24. Yokoyama A, Wang Z, Wysocka J, Sanyal M, Aufiero DJ, Kitabayashi I, Herr W, Cleary ML: Leukemia proto-oncoprotein MLL forms a SETI-like histone methyltransferase complex with menin to regulate Hox gene expression. Mol Cell Biol 2004, 24:5639-5649.

25. Wysocka J, Myers MP, Laherty CD, Eisenman RN, Herr W: Human Sin 3 deacetylase and trithorax-related Set//Ash2 histone H3-K4 methyltransferase are tethered together selectively by the cell-proliferation factor HCF-I. Genes Dev 2003, I 7:896-9|I.

26. Steward MM, Lee JS, O'Donovan A, Wyatt M, Bernstein BE, Shilatifard $\mathrm{A}$ : Molecular regulation of $\mathrm{H} 3 \mathrm{~K} 4$ trimethylation by ASH2L, a shared subunit of MLL complexes. Nat Struct Mol Biol 2006, 13:852-854.

27. Beisel C, Imhof A, Greene J, Kremmer E, Sauer F: Histone methylation by the Drosophila epigenetic transcriptional regulator Ash I. Nature 2002, 41 9:857-862.

28. Byrd KN, Shearn A: ASHI, a Drosophila trithorax group protein, is required for methylation of lysine 4 residues on histone H3. Proc Natl Acad Sci USA 2003, I 00: I I 535-I I 540.

29. Klymenko T, Muller J: The histone methyltransferases Trithorax and Ash I prevent transcriptional silencing by Polycomb group proteins. EMBO Rep 2004, 5:373-377.

30. Furlong EE, Andersen EC, Null B, White KP, Scott MP: Patterns of gene expression during Drosophila mesoderm development. Science 200I, 293:1629-1633.

31. White KP, Rifkin SA, Hurban P, Hogness DS: Microarray analysis of Drosophila development during metamorphosis. Science 1999, 286:2179-2184.

32. Ashburner M, Ball CA, Blake JA, Botstein D, Butler H, Cherry JM, Davis AP, Dolinski K, Dwight SS, Eppig JT, et al:: Gene ontology: tool for the unification of biology. The Gene Ontology Consortium. Nat Genet 2000, 25:25-29.

33. The Gene Ontology Project [http://www.geneontology.org/]

34. Tripoulas N, Lajeunesse D, Gildea J, Shearn A: The Drosophila ash I gene product, which is localized at specific sites on polytene chromosomes, contains a SET domain and a PHD finger. Genetics 1996, 143:913-928.

35. Edgar R, Domrachev M, Lash AE: Gene Expression Omnibus: NCBI gene expression and hybridization array data repository. Nucleic Acids Res 2002, 30:207-210.

36. The Gene Expression Omnibus Database [http:// www.ncbi.nlm.nih.gov/projects/geo/]

37. Klebes A, Sustar A, Kechris K, Li H, Schubiger G, Kornberg TB: Regulation of cellular plasticity in Drosophila imaginal disc cells by the Polycomb group, trithorax group and lama genes. Development 2005, 132:3753-3765.

38. Butler MJ, Jacobsen TL, Cain DM, Jarman MG, Hubank M, Whittle JR, Phillips $R$, Simcox A: Discovery of genes with highly restricted expression patterns in the Drosophila wing disc using DNA oligonucleotide microarrays. Development 2003, 130:659-670.

39. Simmonds AJ, Brook WJ, Cohen SM, Bell JB: Distinguishable functions for engrailed and invected in anterior-posterior patterning in the Drosophila wing. Nature 1995, 376:424-427.

40. Milan M, Weihe U, Tiong S, Bender W, Cohen SM: msh specifies dorsal cell fate in the Drosophila wing. Development 200I, I 28:3263-3268.

41. Ringrose L, Rehmsmeier M, Dura JM, Paro R: Genome-wide prediction of Polycomb/Trithorax response elements in Drosophila melanogaster. Dev Cell 2003, 5:759-77I. 
42. Williams JA, Bell JB, Carroll SB: Control of Drosophila wing and haltere development by the nuclear vestigial gene product. Genes Dev 1991, 5:248I-2495

43. Agrawal N, Joshi S, Kango M, Saha D, Mishra A, Sinha P: Epithelia hyperplasia of imaginal discs induced by mutations in Drosophila tumor suppressor genes: growth and pattern formation in genetic mosaics. Dev Biol 1995, 169:387-398.

44. Paumard-Rigal S, Zider A, Vaudin P, Silber J: Specific interactions between vestigial and scalloped are required to promote wing tissue proliferation in Drosophila melanogaster. Dev Genes Evol 1998, 208:440-446.

45. Datar SA, Jacobs HW, de la Cruz AF, Lehner CF, Edgar BA: The Drosophila cyclin D-Cdk4 complex promotes cellular growth. EMBO J 2000, 19:4543-4554.

46. Moon NS, Frolov MV, Kwon EJ, Di Stefano L, Dimova DK, Morris EJ Taylor-Harding B, White K, Dyson NJ: Drosophila E2FI has context-specific pro- and antiapoptotic properties during development. Dev Cell 2005, 9:463-475.

47. Goodliffe JM, Wieschaus E, Cole MD: Polycomb mediates Myc autorepression and its transcriptional control of many loci in Drosophila. Genes Dev 2005, 19:2941-2946.

48. Badenhorst P, Xiao H, Cherbas L, Kwon SY, Voas M, Rebay I, Cherbas P, Wu C: The Drosophila nucleosome remodeling factor NURF is required for Ecdysteroid signaling and metamorphosis. Genes Dev 2005, I 9:2540-2545.

49. Pile LA, Spellman PT, Katzenberger RJ, Wassarman DA: The SIN3 deacetylase complex represses genes encoding mitochondrial proteins: implications for the regulation of energy metabolism. I Biol Chem 2003, 278:37840-37848.

50. Sierra J, Yoshida T, Joazeiro CA, Jones KA: The APC tumor suppressor counteracts beta-catenin activation and $\mathrm{H} 3 \mathrm{~K} 4 \mathrm{meth}$ ylation at Wnt target genes. Genes Dev 2006, 20:586-600.

5I. Sif S, Saurin AJ, Imbalzano AN, Kingston RE: Purification and characterization of mSin3A-containing Brg I and hBrm chromatin remodeling complexes. Genes Dev 200I, I5:603-6I8.

52. Nakamura T, Mori T, Tada S, Krajewski W, Rozovskaia T, Wassell R, Dubois G, Mazo A, Croce CM, Canaani E: ALL-I is a histone methyltransferase that assembles a supercomplex of proteins involved in transcriptional regulation. Mol Cell 2002, 10:1119-1128.

53. Wysocka J, Swigut T, Xiao H, Milne TA, Kwon SY, Landry J, Kauer M, Tackett A], Chait BT, Badenhorst P, et al:: A PHD finger of NURF couples histone $\mathrm{H} 3$ lysine 4 trimethylation with chromatin remodelling. Nature 2006, 442:86-90.

54. Schuetz A, Allali-Hassani A, Martin F, Loppnau P, Vedadi M, Bochkarev A, Plotnikov AN, Arrowsmith CH, Min J: Structural basis for molecular recognition and presentation of histone H3 by WDR5. EMBO J 2006, 25:4245-4252.

55. Ruthenburg AJ, Wang W, Graybosch DM, Li H, Allis CD, Patel DJ, Verdine GL: Histone $\mathbf{H} 3$ recognition and presentation by the WDR5 module of the MLLI complex. Nat Struct Mol Biol 2006, I 3:704-7|2.

56. De Nadal E, Zapater M, Alepuz PM, Sumoy L, Mas G, Posas F: The MAPK Hog I recruits Rpd3 histone deacetylase to activate osmoresponsive genes. Nature 2004, 427:370-374.

57. Breiling A, Turner BM, Bianchi ME, Orlando V: General transcription factors bind promoters repressed by Polycomb group proteins. Nature 2001, 41 2:651-655.

58. Kurdistani SK, Robyr D, Tavazoie S, Grunstein M: Genome-wide binding map of the histone deacetylase Rpd3 in yeast. Nat Genet 2002, 3 I:248-254.

59. Nakayama J, Rice JC, Strahl BD, Allis CD, Grewal SI: Role of histone H3 lysine 9 methylation in epigenetic control of heterochromatin assembly. Science 2001, 292: I I0-113.

60. Waltzer L, Bienz M: Drosophila CBP represses the transcription factor TCF to antagonize Wingless signalling. Nature 1998 395:521-525.

61. Bantignies F, Goodman RH, Smolik SM: Functional interaction between the coactivator Drosophila CREB-binding protein and $\mathrm{ASHI}$, a member of the trithorax group of chromatin modifiers. Mol Cell Biol 2000, 20:9317-9330.

62. Petruk S, Sedkov Y, Smith S, Tillib S, Kraevski V, Nakamura T, Canaani $E$, Croce CM, Mazo A: Trithorax and dCBP acting in a complex to maintain expression of a homeotic gene. Science 2001 , 294: $133 \mid-1334$.

63. Shearn A: The ash-I, ash-2 and trithorax genes of Drosophila melanogaster are functionally related. Genetics 1989 | 21:517-525.
64. Rozovskaia T, Tillib S, Smith S, Sedkov Y, Rozenblatt-Rosen O, Petruk S, Yano T, Nakamura T, Ben-Simchon L, Gildea J, et al.: Trithorax and ASH I interact directly and associate with the trithorax group-responsive bxd region of the Ultrabithorax promoter. Mol Cell Biol 1999, 19:644I-6447.

65. Kuzin B, Tillib S, Sedkov Y, Mizrokhi L, Mazo A: The Drosophila trithorax gene encodes a chromosomal protein and directly regulates the region-specific homeotic gene fork head. Genes Dev 1994, 8:2478-2490.

66. Schneider J, Wood A, Lee JS, Schuster R, Dueker J, Maguire C, Swanson SK, Florens L, Washburn MP, Shilatifard A: Molecular regulation of histone $\mathrm{H} 3$ trimethylation by COMPASS and the regulation of gene expression. Mol Cell 2005, I 9:849-856.

67. Schlichter A, Cairns BR: Histone trimethylation by Set I is coordinated by the RRM, autoinhibitory, and catalytic domains. EMBO J 2005, 24: | 222-I23|

68. Ryder E, Blows F, Ashburner M, Bautista-Llacer R, Coulson D, Drummond J, Webster J, Gubb D, Gunton N, Johnson G, et al.: The DrosDel collection: a set of $P$-element insertions for generating custom chromosomal aberrations in Drosophila melanogaster. Genetics 2004, 167:797-8I3.

69. Brand $A H$, Perrimon N: Targeted gene expression as a means of altering cell fates and generating dominant phenotypes. Development 1993, I I 8:401-4I5.

70. Mahajan SS, Johnson KM, Wilson AC: Molecular cloning of Drosophila HCF reveals proteolytic processing and self-association of the encoded protein. J Cell Physiol 2003, I 94: I I7-I 26.

7I. Wang HY, Malek RL, Kwitek AE, Greene AS, Luu TV, Behbahani B, Frank B, Quackenbush J, Lee NH: Assessing unmodified 70-mer oligonucleotide probe performance on glass-slide microarrays. Genome Biol 2003, 4:R5.

72. Smyth GK: Linear models and empirical Bayes methods for assessing differential expression in microarray experiments. Stat Appl Genet Mol Biol 2004, 3:. Article 3

73. Gentleman RC, Carey VJ, Bates DM, Bolstad B, Dettling M, Dudoit S, Ellis B, Gautier L, Ge Y, Gentry J, et al.: Bioconductor: open software development for computational biology and bioinformatics. Genome Biol 2004, 5:R80.

74. Futschik ME, Crompton T: OLIN: optimized normalization, visualization and quality testing of two-channel microarray data. Bioinformatics 2005, 21 : I724-1726.

75. Benjamini Y, Drai D, Elmer G, Kafkafi N, Golani I: Controlling the false discovery rate in behavior genetics research. Behav Brain Res 200I, I 25:279-284.

76. Gene Ontology Scripts [http://www.ub.edu/epidd/arrays/GOs cripts/]

77. Xu T, Rubin GM: Analysis of genetic mosaics in developing and adult Drosophila tissues. Development 1993, I I 7:| 223-1237.

78. Pennetta G, Pauli D: The Drosophila Sin3 gene encodes a widely distributed transcription factor essential for embryonic viability. Dev Genes Evol 1998, 208:531-536. 